\title{
Public policy action and CCC implementation: benefits and hurdles
}

\author{
Carter Steger · Kelley Daniel · Gary L. Gurian • \\ J. T. Petherick · Chris Stockmyer - Annette M. David · \\ Sara E. Miller
}

Received: 3 June 2010/ Accepted: 8 October 2010/Published online: 18 November 2010

(C) The Author(s) 2010. This article is published with open access at Springerlink.com

\begin{abstract}
Policy change continues to be an increasingly effective means of advancing the agenda of comprehensive cancer control. Efforts have moved progressively from describing how public policy can enhance the comprehensive cancer control agenda to implementation of public policy best practices at both the state and federal levels. The current political and economic contexts bring additional challenges and opportunities to the efforts surrounding comprehensive cancer control and policy. The purpose of this paper is to highlight recent policy successes, to illustrate the importance of policy as a means of advancing the comprehensive cancer control agenda, and to discuss
\end{abstract}

The findings and conclusions in this report are those of the authors and do not necessarily represent the views of the Centers for Disease Control and Prevention.

C. Steger $(\bowtie) \cdot$ K. Daniel

State and Local Campaigns, American Cancer Society Cancer Action Network, 901 E Street, NW Suite 500, Washington, DC 2004, USA

e-mail: csteger@cancer.org

G. L. Gurian

C-Change, Washington, DC, USA

J. T. Petherick

Cherokee Nation, Tahlequah, OK, USA

C. Stockmyer

Division of Cancer Prevention and Control, Centers for Disease Control and Prevention, Atlanta, GA, USA

A. M. David

Health Partners, LLC, Tamuning, Guam, USA

S. E. Miller

Colorado Foundation for Public Health and the Environment, Highlands Ranch, CO, USA continued policy action as we move forward in a time of healthcare reform and continuing economic uncertainty.

Keywords Comprehensive cancer - Public policy · Coalition

\section{Introduction}

In 1998, Centers for Disease Control and Prevention (CDC) established the National Comprehensive Cancer Control Program (NCCCP), which provides seed money and technical support for the development and implementation of comprehensive cancer control plans. Key components of effective comprehensive cancer control (CCC) include the use of public health policy, environmental and systems level change. Policy issues that are important in reducing the burden of cancer include, but are not limited to: cancer screening (e.g., breast, cervical, colorectal), medical coverage, tobacco excise taxes, smoke-free laws, tobacco cessation services, indoor tanning device regulation, policies to improve nutrition and increase physical activity, and patient navigation. Policy change is a particularly useful strategy for implementing CCC plans because policy change affects large numbers of people. Policy change eliminates or creates barriers that support individual healthy choices and can also provide substantial revenues to enhance CCC activities and objectives. Policy change potentially provides a context promoting healthy individual choices to further enhance CCC objectives.

Policy and its impact on comprehensive cancer control have been addressed in a previous publication of this journal in 2005 [1]. Since then, comprehensive cancer control efforts in many states, tribe or tribal organizations, territories and Pacific Island Jurisdictions have benefited from 
public policy work to improve smoke-free laws, increase tobacco taxes, and provide funding for colorectal cancer screening programs as illustrated throughout this supplement. For the purposes of this article, "public policy" can be defined as "the concerted action of governments and other institutions to use mechanisms of influence or control to achieve a desired outcome. They apply to large sectors or populations and set the context in which individual decisions and actions are made" [2]. For clarity, it should be further recognized that this article does not discuss organizational policy change or environmental change, but rather discusses specifically the benefits and challenges for CCC that accompany governmental policy action. Thus, efforts to enact a statute, to implement a rule or regulation or to initiate actions taken by an elected or appointed body that affects a specific constituency are the subject matter discussed here. The actions of elected officials are supplemented with efforts that are implemented through citizen initiative in those states that allow such action.

In this article, policy activities will be considered in light of the role of three different entities working to implement CCC: CDC's NCCCP, the Comprehensive Cancer Control National Partnership (CCCNP), and comprehensive cancer control coalitions. Since much of the work is actually done by the CCC coalitions, the third section of this article highlights recent notable successes and the challenges faced by coalitions as they work to pass policy beneficial to CCC. More detailed examples of policy change made through coalition efforts in Guam, Cherokee Nation, and Colorado are provided to further illustrate the benefits and challenges of policy action. Finally, future directions are noted and conclusions drawn.

\section{Implementing CCC: the national comprehensive cancer control program}

In 1998, the Centers for Disease Control and Prevention (CDC) established the NCCCP, which provides funding and technical support for the development and implementation of comprehensive cancer control plans (CDC-RFA-DP07703). Currently 50 states, the District of Columbia, 7 tribes or tribal organizations, 7 US territories, and Pacific Island Jurisdictions (PIJ) receive NCCCP funding. The funding is typically used to develop the infrastructure for a CCC program (i.e., salary and benefits for a fulltime program director and usually a part-time health educator, evaluator, administrative support person and/or other position). This infrastructure is needed to carry out several required activities for the NCCCP, which include building and sustaining partnership support to develop and implement a CCC plan. The CCC plan is the mechanism for coalition members to address cancer priorities for their state, tribe or tribal organization, territory, or PIJ. CCC coalition members are involved in the development of the plan and use it, for example, to educate and inform state and local legislatures, as well as other cancer stakeholders. Implementation of the plan utilizes not only federal investments but investments such as direct funding or in-kind support from states, localities, and national non-governmental organizations. Federal funds are also used to develop the plan and support monitoring of plan implementation.

In addition to building the CCC infrastructure, another $\mathrm{CDC}$ required activity is to effect policy change. It should be noted that federal funds can be used to educate and inform CCC coalition members, but they cannot be used to support lobbying. CDC supports evidence-based policy change strategies by encouraging its grantees to provide CCC coalition members with the information and the evidence base around policies that will have the greatest public health impact. CCC coalitions may want to consider using a framework developed by Thomas R. Frieden as they develop or update their policy agenda. Frieden's "Health Impact Pyramid" framework identifies interventions (to include policies) that have the greatest population impact [3]. A five-tier pyramid was developed to illustrate the amount of individual effort needed and the population impact that may result from implementing interventions represented by each tier. The five tiers are (listed from the base of the pyramid to the top): socioeconomic factors (e.g., income, education); changing the context to make individual default decisions healthy (e.g., policies that encourage public transportation, bicycling and walking instead of driving; passing smoke-free laws; taxing tobacco, alcohol, and unhealthy foods such as sugar sweetened beverages); long-lasting protective interventions (e.g., colonoscopy, smoking cessation, immunization); clinical interventions (e.g., using electronic health records to change physician practices); and counseling and education. Interventions at the base of the pyramid require the least individual effort and have the largest population impact.

CDC uses performance measures with its grantees to determine the extent to which required activities are being achieved. To determine whether grantees are affecting policy change they are asked to specify, track, and report state and local-level policy changes in cancer prevention and control. In response to this, grantees annually submit policy changes that were achieved with a contribution from the comprehensive cancer partnership as part of the annual performance report required by the funding opportunity. During the last reporting period (30 June 2008-29 June 2009), 271 policy changes were self-reported as 59 out of 69 programs submitted policy data. CDC funds 65 programs, one of which is the Federated States of Micronesia. National FSM and its 4 states submit data separately, which brings the total to 69 . 
Although standardized categories were not provided, these data show that almost three-quarters of programs reporting are working on policies that address tobacco $(n=42)$; one-third to one-quarter are working on treatment and care $(n=23)$, colorectal cancer screening $(n=$ $19)$, breast and cervical cancer screening $(n=14)$ or nutrition/physical activity $(n=13)$; and some are working on skin cancer $(n=8)$, palliative care $(n=7)$ or prostate cancer $(n=4)$ [4]. These initial data are valuable, and CDC is committed to working with grantees to standardize the reporting of policy change. Current and future policy data collected will be useful in monitoring the impact of CCC coalitions across the nation.

\section{Implementing CCC: the comprehensive cancer control national partnership}

Policy work and change provides multiple opportunities for CCC coalitions to further their cause. This has been recognized by the CCCNP, a group of national organizations dedicated to leveraging resources and coordinating cancer expertise to collectively support CCC. The CCCNP includes the American Cancer Society, the American Cancer Society Cancer Action Network, the American College of Surgeons Commission on Cancer, Association of State and Territorial Health Officers, C-Change, the Centers for Disease Control and Prevention, Health Resources and Services Administration, the Intercultural Cancer Council, Livestrong, Leukemia and Lymphoma Society, the National Association of Chronic Disease Directors, the National Association of City and County Health Officials, the North American Association of Central Cancer Registries, the National Cancer Institute and Susan G. Komen for the Cure. (For more on the National Partnership see the article "Comprehensive Cancer Control: Progress and Accomplishments" in this edition of the journal.)

In 2008 and 2009, the CCCNP held three comprehensive cancer control policy and practice summits for comprehensive cancer control coalitions: (1) state, (2) tribes or tribal organizations, and (3) territories and PIJ. At these policy and practice summits, coalition members identified policy needs in their locales. Based upon the policy needs identified at specific policy summits, the CCCNP recognized that the policy actions and the implementation of the identified needs would be of interest to all CCC coalitions. Thus, the CCCNP have developed a policy agenda that is based on the identified needs made by coalition attendees at these policy summits. Table 1 includes the CCCNP policy agenda items, the policy summit where the items were first suggested and whether the item is ready for policy action or currently in the study phase.
The first phase for many of the listed agenda items is to study and determine how the CCCNP might be most effective and most helpful to CCC coalitions. Consequently, many policy agenda items are currently in the study phase since the CCCNP have only recently begun to develop a policy agenda. During the study phase, the CCCNP intend to identify the appropriate actions to take and determine how individual partners might best assist CCC coalitions in the policy process. In coming months and years, it is anticipated that various CCCNP organizations will choose actions specifically suited to their organizational goals and then support CCC coalitions in implementing those policy actions. The ultimate goal of the CCCNP is to provide information, technical support, and guidance to CCC coalitions as they move forward on policy change and plan implementation.

\section{Implementing CCC: the comprehensive cancer control coalitions}

In addition to national policy work, a significant amount of policy work is done by CCC coalitions at the state, tribal, and PIJ level. Coalition activities in the public policy realm provide opportunities to build momentum for the CCC cause with potential benefit for many individuals such as smoke-free air, reduced youth use of tobacco following a tax increase and increased access to colorectal cancer screenings following from a single successful public policy action. Multiple challenges with coalition work must be overcome before success is achieved. This section discusses recent successes for policy and CCC in a broad sense, notes the difficulties faced by coalitions and posits some means of overcoming the difficulties.

\section{Examples of recent successes}

The National Breast and Cervical Cancer Early Detection Program (NBCCEDP) and the Breast and Cervical Cancer Prevention and Treatment Act (BCCPTA) are examples of far-reaching federal legislation, which have benefited women. The NBCCEDP has resulted in over eight million exams for three million underserved women. All 50 states and the District of Columbia provide treatment for those diagnosed under NBCCEDP through the BCCPTA [5]. These programs have also prompted state policy makers to be aware of the importance of cancer prevention and treatment. Even long-standing programs such as these have benefited from the concerted efforts from both lobbyists and advocates to maintain or increase funding in appropriations during tough economic times. For example, appropriation trends among the states and the District of Columbia (DC) for the NBCCEDP from 2009 to 2010 
Table 1 CCC National Partner Policy agenda items, originating summit and current status

\begin{tabular}{|c|c|c|}
\hline Policy agenda item & Summit & Status \\
\hline $\begin{array}{l}\text { Advocate for continued and coordinated Federal, state, and local support for CCC programs } \\
\text { and coalitions }\end{array}$ & State & Active \\
\hline Identify policies to help implement health care reform & State & Study \\
\hline $\begin{array}{l}\text { Improved integration of CCC with other chronic disease programs (i.e., diabetes, heart disease) } \\
\text { to maximize AI/AN CCC efforts }\end{array}$ & $\mathrm{AI} / \mathrm{AN}$ & Study \\
\hline $\begin{array}{l}\text { Promote changes to the health system, including universal patient navigation, that will lead to better } \\
\text { cancer outcomes for AI/AN people }\end{array}$ & $\mathrm{AI} / \mathrm{AN}$ & Study \\
\hline Consider options for federal agencies to hold states more accountable for how they relate to tribes & $\mathrm{AI} / \mathrm{AN}$ & Study \\
\hline $\begin{array}{l}\text { Increase flexibility of funds to allow jurisdictions to proactively negotiate agreements and allocate } \\
\text { funding to high priorities }\end{array}$ & Territories and PIJ & Study \\
\hline Eliminate caps for Medicaid, work to implement increased local/state match & Territories and PIJ & Study \\
\hline Implement minimum standard credentials for all health agency workers & Territories and PIJ & Study \\
\hline
\end{tabular}

show that 13 programs reported funding increases and 22 reported level funding [6]. The current recession has made it more difficult to maintain level funding from state legislatures as other policy priorities compete with CCC efforts. For those states where funding increases have occurred, the success and need for the programs are emphasized by advocates, and legislators understand the importance of the programs and CCC benefits.

Mandates requiring coverage of colorectal cancer screenings by private insurers are in place in many states, which benefit comprehensive cancer control programs. Colorectal cancer prevention and treatment has also seen significant advances in the recent past due to policy action. Currently, 27 states and DC have laws that ensure comprehensive coverage for the full range of colorectal cancer screening tests [7]. Federal appropriations for CDCsupported colorectal cancer control programs have also increased, which has allowed expansion of funding to expand from five sites in 2005 to 25 states and three tribal organizations in 2009.

Comprehensive smoke-free laws cover entire jurisdictions and hundreds of thousands or millions of people, depending on the size of the municipality or state. Efforts to pass smoke-free laws have been more successful in recent years. As of 5 July 2010, 22 states and DC will be 100 percent smoke-free in workplaces, restaurants, and bars [8]. In 2002, only Delaware had such a comprehensive law. Significant successes have also occurred with tobacco taxes. In 2009 alone 14 states, the DC and Puerto Rico raised their taxes. In 2010, six more states and Guam will have increased their taxes by 1 July [9]. The average state tobacco excise tax will be $\$ 1.45$ per pack as of 1 July 2010 compared to slightly over 43 cents per pack as of 31 December 2001 [10]. These efforts in tobacco control will benefit CCC efforts around the country as fewer youth start smoking and more adults try to quit. More specifically, South Carolina worked for 10 years before finally increasing the cigarette tax in 2010 and getting some of the revenues dedicated to tobacco control.

Federal appropriations for the National Institutes of Health (NIH) have been increased through the efforts of groups such as the American Cancer Society Cancer Action Network (ACS CAN) and One Voice Against Cancer (OVAC) with some of these dollars benefiting CCC efforts. At the state level, cancer control research increased in Texas where citizens approved increased revenues for research with the passage of Cancer Prevention and Research Institute of Texas (CPRIT) Act in 2007. The Act allowed the "State of Texas to establish the Cancer Prevention and Research Institute of Texas (the Institute) and allows the Institute to issue $\$ 3$ billion in general obligation bonds over 10 years to fund grants for cancer research and prevention. The Institute may invest the grants strategically in cancer research, clinical trials, and laboratory facility construction in Texas" [11].

\section{Challenges faced in coalition policy work}

Even policy which seems inherently "good" will likely run into organized opposition in the political arena because it takes additional time to educate policy makers and pass the policy through a complex lawmaking process. Other public policy groups will also be actively working to have their priorities met in a situation of limited resource availability. As noted previously, South Carolina's 10-year effort shows that a major policy initiative rarely becomes law on the first attempt even with educated advocates and legislators.

Furthermore, it must be recognized that passing legislation is only the first step. Effective implementation and enforcement of new legislation is as important as passing it. In some cases, it is often as difficult as passage since the language in the legislation is rarely specific and must be enforced by agencies with their own agendas. Those 
advocating for change must follow through and be vigilant as the implementation process moves forward. Advocates must take the time and make the effort to be certain the policy is implemented as intended. Additionally, policies that are passed must be continually defended as every legislative session offers another opportunity for opponents to rewrite or amend the language that comprehensive cancer control advocates fought so hard to pass. This has become particularly apparent in the current cash-strapped fiscal environment at the state and federal levels. Nearly, all states must balance their budgets so it is easy to see how a recession might place revenues at risk. This is also true at the Federal level as political pressures and competing interests may focus revenue needs into areas other than comprehensive cancer control.

To successfully pass policy, coalitions must overcome factors external to the coalition such as fiscal challenges and the potential conflict with other advocacy groups. Coalitions also face internal challenges such as issue prioritization, agenda-setting, and the tensions that arise when some coalition members are able to lobby and others are not.

Public policy opportunities are still worthwhile to pursue despite the challenges as it strengthens the coalitions' work to implement comprehensive cancer control. Successful policy change has allowed us to make significant gains for $\mathrm{CCC}$ in the last 5 years. Three best practice examples are provided to help illustrate how various coalitions have worked on legislation to make significant progress in CCC.

\section{Guam}

In Guam, an unincorporated Territory of the United States, cancer is the second leading cause of death and unlike the US mainland, cancer incidence and mortality are increasing [12]. Its 170,000 people have the highest adult smoking rate of all US states and territories [13].Not surprisingly, tobacco-related cancers head the list of cancer mortality [14].

Raising tobacco taxes is one of the most effective interventions to curb tobacco use within a population [15]. Over time, the reduction in consumption can lead to significant decreases in the incidence of tobacco-related cancers, and consequently, tobacco-related cancer mortality. The World Health Organization recommends using tobacco taxes to fund health promotion and prevention through mechanisms that earmark tax revenues for health [16]. In Guam, the opportunity arose in 2009 to link a proven tobacco control intervention-raising tobacco prices through taxation-to provide sustainable local funding for cancer prevention and control through earmarked tax revenues. The Guam Comprehensive Cancer Control Coalition recognized this opportunity and proactively sought to make it happen; one of its member coalitions, the Tobacco Control Coalition, wrote it into its work plan.

In mid-2009, one of Guam's Senators proposed a bill to raise tobacco taxes by $\$ 0.50$ per cigarette pack (with commensurate increases for other tobacco products) to augment tax revenues for the Government of Guam. Upon learning about this bill, the coalition immediately convened a technical working group comprised of legal counsel, legislative staff of the bill's author, tobacco control experts, tobacco and cancer control program managers, and community advocates. After reviewing the original bill, the group resolved to advocate for the following revisions to the bill: (1) augment the proposed tax increase from $\$ 0.50 /$ pack to at least $\$ 1.00 /$ pack (the last tobacco tax increase on Guam occurred in 2003, which raised tobacco taxes from $\$ 0.07 /$ pack to $\$ 1.00 /$ pack); (2) earmark a portion of the tax revenues for cancer prevention and control, including tobacco control; and, (3) delete the provision in the bill requiring a general referendum for passage into law, given the urgency of the cancer situation on the island.

The coalition was fully aware that any proposal to raise tobacco taxes would generate strong opposition from the tobacco distributors and wholesalers, who comprise a small but politically powerful group on the island. (Note: There are no tobacco manufacturers on Guam; the island imports all of its tobacco products.) In its original version, the bill would likely not survive in the Legislature. However, because cancer and the costs of health care are priority issues for the Guam community, the coalition believed that linking the tax increase to cancer prevention and control funding support provided a viable alternative to "frame" the issue for successful passage.

The coalition decided on a two-pronged tactical approach —on one front, it offered to assist the Senator's legislative drafting team in finalizing the legal language for a revised Bill, and by doing so, gained entrance into the internal process within the Legislature, enabling it to monitor the bill's progress. On another front, the community advocates within the coalition began to mobilize wider community support for the tax increase as a sustainable local solution to address funding for cancer prevention and control.

Two groups of advocates played critical roles in the passage of Bill 150. The first group was comprised of members of the health community, particularly physicians, who appeared en masse during the public hearings and who provided compelling written and verbal testimony about the data and evidence underpinning the revised Bill. The second important group of advocates was made up of cancer patients and their families, who spoke at the public hearings and in media about their struggles to deal with 
their disease and who, through their stories, put a very real "face" to the issue. These advocates served as the "tipping point" for the revised Bill, because through their efforts, the undecided members of the Legislature were convinced to support the Bill.

The Bill was successfully passed by the Legislature on 22 January 2010. To date, this represents the single largest one-time tobacco tax increase within the United States and its Territories. Taxes increased by $\$ 2.00$ per pack (with corresponding increases for other tobacco products), double the amount originally recommended by the coalition. Fifteen percent of tax revenues were earmarked into a special fund for cancer care, with an additional 1 percent of revenues allocated to fund the Guam Cancer Registry. Separate from the General Fund, 72 percent of the revenues went into the Healthy Futures Fund and was designated for tobacco, alcohol and drug prevention, health promotion and tobacco cessation. It is also the first time that a tobacco tax will be linked to sustainable local funding for health care and prevention on Guam.

On 7 April 2010, the increased tax for tobacco products went into effect. Already, calls to Guam's Quitline and requests for tobacco cessation services at the Department of Mental Health and Substance Abuse have increased. The coalition will be monitoring the impact of this law on tobacco consumption and funding for cancer care over time.

\section{Cherokee Nation}

The Cherokee Nation is the second largest tribe in the United States with over 278,000 citizens and a jurisdictional area spanning over 7,000 square miles throughout a 14-county area in north eastern Oklahoma.

The Cherokee Nation strives toward achieving and maintaining an enriching cultural identity, an economic self-reliance, and a strong government. As part of this vision, the Cherokee Nation's Declaration of Designed Purpose (100 year plan) calls for the following Tribal Initiatives:

- Jobs (Creation of new jobs and training for individual capacity building)

- Community (Building healthy communities)

- Language (Promote Cherokee Language and Preserve our Culture)

In order to achieve this vision, building and sustaining healthy communities is a strategic priority for the Cherokee Nation, including the Cherokee Nation CCC Coalition. However, the Cherokee Nation realizes that no single intervention will work and recognizes the relationship between people, their social networks, and environments and how they can have a positive, or negative, impact on making lifestyle decisions. Policy development plays a key role in achieving this vision.

Over the past several years, the Cherokee Nation CCC Coalition has focused on policy development and its role in building healthier communities and addressing the health needs of its population, especially in cancer prevention, treatment, and control. The Cherokee Nation has undertaken a historical review of previous policy decisions and realized that policy makers often created policies with the best intentions; however, their efforts often focused on addressing individual behavior change as opposed to the complex mix of community environments that impact individual behaviors. As a result, the policy change had only a minimal impact on a few individuals and did not create an atmosphere for sustained change. Armed with a new perspective on policy development, the Cherokee Nation has made substantial progress in recent years and the Cherokee Nation CCC Coalition is utilizing this perspective to update its CCC plan.

On 1 October 2007, the Cherokee Nation implemented a policy establishing a tobacco-free environment. Smoking and other tobacco use is prohibited on all Cherokee Nation owned, leased and rented property (exceptions exist for gaming sites and ceremonial use). All smoking areas on Cherokee Nation grounds were converted for other uses. In order to ensure the policy actually reduced tobacco use within the Cherokee Nation, the Cherokee Nation provides tobacco cessation classes as well as many health-promoting activities to employees and members of the community throughout the year, including health fairs, exams, stickball, healthy cooking courses, nutrition counseling and more. During this period, the Cherokee Nation also opened a recreation center in Tahlequah, which is free to all Cherokee Nation employees and their families, as well as area American Indians. Community members not eligible for free membership may join for a nominal monthly fee.

The Cherokee Nation is also undertaking a community campaign to combat obesity, smoking, and other preventable health risks. Along with its existing tobacco use prevention efforts, the Cherokee Nation is assisting communities and businesses to implement tobacco-free policies, develop product placement guidelines for tribal-owned businesses and increase access to cessation services for citizens and other residents of tribal areas.

\section{Colorado}

The Colorado Cancer Coalition, the foundational partnership leading comprehensive cancer control efforts in the state, has been active in the policy realm since the passage of a statewide tobacco tax (Amendment 35) in 2004. At the 
time, the coalition was prohibited from taking policy positions as a whole due to its close relationship with the state health department. While the full coalition could not take a position on the tax initiative itself, many of the individual members were actively involved. After the passage of the tax, the coalition moved from the state health department to be an official program of a non-profit organization, the Colorado Foundation for Public Health and the Environment. This allowed the coalition to take a more proactive role in shaping policy in the state.

Since the passage of Amendment 35, the coalition and its partners have actively pursued the tobacco tax revenues that have been coming in, particularly for colorectal cancer and sun safety activities. By 2007, in tobacco programs alone over $\$ 59$ million was distributed to more than 150 non-profit organizations, local public health agencies and county nursing services. In cancer-related programs by 2007 , over $\$ 14$ million was targeted to public and private organizations throughout Colorado. Through 2010, the Colorado colorectal screening program has screened over 10,000 individuals and has educated millions of people about the benefits of colorectal cancer screening.

The recession, which began in 2008, has had major impacts on Colorado's ability to direct funds to activities for cancer control. In 2010, the budget crisis continues to be real and funds are expected, once again, to be diverted to the General Fund and away from the voter-approved grants programs for tobacco control and cardiovascular, cancer and pulmonary disease grants. In late August 2010, the Governor proposed a budget balancing plan to address a $\$ 320$ million revenue shortfall for the state. Unfortunately, the programs funded through the Amendment 35 Tobacco Tax revenues were included in the cuts. This includes both the tobacco control and the early detection and prevention of cancer programs.

The coalition has been able to actively defend the funds and to send various messages through coalition partners to state policy makers indicating the coalition's displeasure with the fund diversions. Email action alerts, letters from the coalition and press releases are among the tactics that have been employed in this effort. Successes included, although reduced drastically, funding for tobacco, breast and cervical cancer screening, and colorectal cancer screening. While the funds have continued to be cut, the coalition has been able to present a united front as they work to maintain these funds. The ability to provide a united coalition "stance" has elevated the coalition in the eyes of legislators and media. Legislators understand that there is a group advocating on behalf of CCC.

The immediate challenge for Colorado is to ensure through the Colorado Cancer Control Coalition that when funding is restored the coalition is well positioned to regain ground lost during these tough times.

\section{CCC coalitions and future policy action}

While the examples and case studies above illustrate the impressive potential of legislative policy action, much work remains. For example, a great deal needs to be done to support racial and ethnic minority populations and reduce the cancer incidence and mortality rates among those populations [17]. For these populations, increased funds designated for access to screening and navigation services, increased and sophisticated research among subpopulations, and increased access to facilities, care and clinical trials will all be important.

Much needs to be done to defend against policy rollbacks and to support expansion of current policy. In the three areas that are important for tobacco control, many states still do not have comprehensive smoke-free laws, several states and their citizens could still benefit by increasing tobacco taxes and for the third leg of the tobacco control stool, North Dakota is the only state that currently funds its tobacco control program at CDC recommended levels [18]. Other important policy arenas must be monitored as well. The NBCCEDP is chronically underfunded, serving only 13.2 percent of eligible women 40-64 years old [19]. As noted with the Colorado mini-case study, CCC priorities, including funding for research are under scrutiny at both the state and federal levels. Those working to improve public policy must be alert and proactive to protect funding for these vital prevention and research efforts. While tribes, territories and PIJs must face the same coalition dynamics and opposition pressures to policy change, they also face unique pressures since they operate in a different political milieu than the states. The relationship between tribes, territories, PIJs and Congress means that they may have less leverage to obtain federal resources than the states do.

\section{Recommendations and future directions}

The movement to utilize public policy changes as a means of improving comprehensive cancer control efforts has been gaining momentum with CCC coalitions. The examples in this paper provide specific and noteworthy examples of the benefits of undertaking public policy action.

As coalitions move forward, it will be important to remember that successful policy change requires concerted efforts among coalition staff, coalition partners and volunteers willing to engage in the policy process. Successful public policy activities require planning, and conscious efforts to build a strong coalition, and planned prioritization among coalition members as to which policy change is most important to undertake and when it should be undertaken. 
Getting to the point where coalition members are prepared for successful policy work also requires skill building in policy work. As resources allow, CCC coalitions may want to build additional capacity to work on policy changes. Ways to do so may include hiring or contracting with dedicated staff with competency in issue framing, policy analysis, policy formulation, message tailoring, and media advocacy. Coordination of these activities with the priorities in the specific CCC cancer plan is necessary for success. A policy workgroup or taskforce may need to be created to support policy change. Policy workgroups or taskforces should engage individuals at the community level in order to identify policy interventions that match the cancer burden and cancer plan priorities at the local level. Development of a policy agenda and identification of planned media strategies are also needed to be successful at impacting policy change. In June 2010, CDC released a new funding opportunity announcement that asks grantees to demonstrate the capacity of its CCC program to implement cancer control policy interventions. Successful applicants will be asked to take capacity building steps similar to those noted in this section (CDC-RFA-DP10-1017).

If policy changes are on the list of a coalition's priorities, it is necessary to train coalition members on messaging, tactics, and the finer points of the political process relevant for the state, tribe, territory, or jurisdiction. The preliminary steps of prioritization and training must be followed by the education of all coalition members, the general public and finally the legislative body, agency or city council with authority to determine the issue's outcome. Planning, training, and education should allow a seamless move into the actual passage of legislation or monitoring of implementation efforts.

As we continue to build coalition capacity and skills to move policy change forward, we also need to continue to communicate lessons learned to our colleagues. The three examples of Guam, the Cherokee Nation and Colorado illustrate the benefits of action in the public policy realm, but much remains to be gained through policy change. CCC coalitions need to work on policies to increase appropriations for screening, increase access to clinical trials, improve tobacco control policies, protect past policy victories and/or implement additional priorities in their respective cancer plans. The future of CCC implementation will depend to a significant degree on expansion of coalition capacity and infrastructure to change policy, the willingness of coalitions to take on public policy change, willingness to monitor and defend public policy successes and to move into those areas that have not yet been explored, including meeting the challenges and opportunities associated with the recently enacted health care reform legislation.
Open Access This article is distributed under the terms of the Creative Commons Attribution Noncommercial License which permits any noncommercial use, distribution, and reproduction in any medium, provided the original author(s) and source are credited.

\section{References}

1. Selig KD et al (2005) Examining advocacy and comprehensive cancer control. Cancer Causes Control 16(Suppl 1):61-68

2. National Association of Chronic Disease Directors website (2010) CDC policy definition. Site accessed 5 Aug 2010, www. chronicdisease.org/files/public/AC_CDC_policy_definition_Mar_ 08.doc

3. Frieden TR (2010) A framework for public health action: the health impact pyramid. Am J Public Health 100:590-595

4. Townsend J (2010) Performance measures for NCCCP-funded programs: how $\mathrm{CDC}$ uses these data and how program directors can use these data. Presented at CDC's NCCCP program director meeting, Los Angeles, CA, Hyatt Regency Century Plaza

5. American Cancer Society Cancer Action Network (2010) How do you measure up?: a progress report on State Legislative Activity to Reduce Cancer Incidence and Mortality, p 17

6. Unpublished data gathered by the American Cancer Society Cancer Action Network in 2009 and 2010

7. American Cancer Society Cancer Action Network (2010) How do you measure up?: a progress report on State Legislative Activity to Reduce Cancer Incidence and Mortality, p 12

8. American Cancer Society Cancer Action Network (2010) How do you measure up?: a progress report on State Legislative Activity to Reduce Cancer Incidence and Mortality, p 23

9. Campaign for Tobacco Free Kids website and fact sheet. Site accessed 29 July 2010. http://www.tobaccofreekids.org/research/ factsheets/pdf/0275.pdf

10. Campaign for Tobacco Free Kids website and fact sheet. Site accessed 29 July 2010. http://www.tobaccofreekids.org/research/ factsheets/pdf/0211.pdf

11. CPRIT website (2010) TCC is now CPRIT. Site accessed 29 July 2010. http://www.cprit.state.tx.us/news.html

12. Guam Cancer Facts and Figures 2003-2007. Department of Public Health and Social Services, Hagatna, Guam

13. Guam State Epidemiological Workgroup (2009) Guam state epidemiological profile 2008 update. Department of Mental Health and Substance Abuse, Prevention and Training Branch, Hagatna, Guam

14. Guam Comprehensive Cancer Control Coalition (2009) Guam cancer facts and figures 2003-2007. Department of Public Health and Social Services, Hagatna, Guam

15. The World Bank (1999) Curbing the epidemic: governments and the economics of tobacco control. The World Bank, Washington

16. World Health Organization Western Pacific Regional Office (2004) The establishment and use of dedicated taxes for health. World Health Organization, Manila

17. American Cancer Society (2010) Cancer facts and figures 2010, p 40

18. Campaign for Tobacco Free Kids website (2010) New report: states cut funding for tobacco prevention programs despite receiving record amounts of tobacco revenue. Press release on site dated 9 Dec 2009. Site accessed 29 July 2010. http://www. tobaccofreekids.org/Script/DisplayPressRelease.php3?Display= 1183

19. Tangka F et al (2006) Cancer Causes Control 17(9):1145-1154 